\title{
OS GÊNEROS DIGITAIS NA BNCC E AS POTENCIALIDADES DO VÍDEO- MINUTO
}

\section{DIGITAL GENRES IN BNCC AND THE POTENTIALITIES OF THE MINUTE- VIDEO}

\author{
Suéllen Rodrigues Ramos da Silva ${ }^{1}$ \\ Danielle Abrantes de Menezes Carvalho ${ }^{2}$ \\ Maria de Lourdes Pereira de Lima $^{3}$ \\ Liliane Cunha da Silva ${ }^{4}$ \\ José Moacir Soares da Costa Filho ${ }^{5}$
}

\begin{abstract}
RESUMO: As novas tecnologias envolvem o ser humano e revolucionam os métodos de ensino-aprendizagem. Logo, o ambiente escolar, associado a um bom planejamento e a educadores qualificados, torna possível ações de inclusão e letramento digital de alunos e professores. A partir de uma revisão bibliográfica, percebe-se que o uso das mídias na educação proporciona aos alunos aprofundar o conhecimento através de pesquisas e buscas que trarão novas compreensões de mundo, como o uso pedagógico de celulares, computadores, internet e outras tecnologias presentes no dia-a-dia, mas que, na escola, podem ser mediadas por educadores na construção de conhecimento, inclusive na disciplina de Língua Portuguesa, a partir de uma concepção de linguagem que tem como base a interação. Para tanto, o trabalho focado em gêneros discursivos, conforme indicam documentos de orientação, como a Base Nacional Comum Curricular - BNCC, abrangendo também os gêneros digitais, é de grande relevância. Dentre esses, o gênero vídeo-minuto merece destaque, diante de suas potencialidades de uso, tanto no campo artístico-literário quanto de práticas de estudo e pesquisa.
\end{abstract}

PALAVRAS-CHAVE: BNCC. Gêneros digitais. Vídeo-minuto. Minuto Lumière.

ABSTRACT: The new technologies involve the human being and change the methods of learning and teaching. Thus, the school environment, associated to a good planning and to qualified educators, enables learners and teachers to participate in inclusive practices of digital literacy. Based on a literature review, it is noticeable that the use of medias in education helps the students to achieve a deeper knowledge through research that may bring a new comprehension of the world. As examples of that, the pedagogical use of cell phones, computers, internet, and other technologies present in daily routine, which, in school, may be mediated by educators during knowledge construction, including the subject of Portuguese Language, from a language conception based in the social interaction. Therefore, the work focused on discursive genres has a great relevance, as indicated in guidance documents, such as the Common National Curriculum Base - BNCC, also covering the digital genres. Among these genres, the genre one-minute video deserves attention due to its potential use not only in artistic-literary field but also the field of study and research practices.

KEYWORDS: BNCC. Digital genres. Minute-video. Lumière Minute.

\footnotetext{
${ }^{1}$ Doutora e Mestra em Letras pelo Programa de Pós-graduação em Letras da Universidade Federal da Paraíba (PPGL/UFPB). Graduada em Jornalismo (UFPB). Graduanda em Letras, habilitação em Língua Portuguesa, pelo Instituto Federal de Educação, Ciência e Tecnologia da Paraíba (IFPB). E-mail: suellenrodrigues.rs@gmail.com ${ }^{2}$ Especialista em Gestão Pública Municipal pela Universidade Federal da Paraíba (UFPB). Graduada em Turismo (UFPB). Graduanda em Letras, habilitação Língua Portuguesa, pelo Instituto Federal de Educação, Ciência e Tecnologia da Paraíba (IFPB). E-mail: danielleabrantestur@gmail.com

${ }^{3}$ Especialista em Psicopedagogia Institucional, pelo Instituto Superior de Cajazeiras (ISEC). Licenciada em Pedagogia pela Universidade Estadual Vale do Acaraú (UVA). Graduanda em Letras, habilitação Língua Portuguesa, pelo Instituto Federal de Educação, Ciência e Tecnologia da Paraíba (IFPB). E-mail: lourdes134lima@gmail.com

${ }^{4}$ Especialista em Neuropsicopedagogia e Ensino Especial, pelo Instituto de Ciências Sociais e Humanas (ICSH). Bacharela em Psicopedagogia, pela Universidade Federal da Paraíba (UFPB). Graduanda em Letras, habilitação Língua Portuguesa, pelo Instituto Federal de Educação, Ciência e Tecnologia da Paraíba (IFPB). E-mail: liliane.cunha.lcs@gmail.com

${ }^{5}$ Doutor e Mestre em Linguística pelo Programa de Pós-Graduação em Linguística (PROLING) da Universidade Federal da Paraíba (UFPB). Professor efetivo do Instituto Federal de Educação, Ciência e Tecnologia da Paraíba (IFPB). E-mail: jmscostafilho@gmail.com.
} 


\section{Introdução}

$\mathrm{O}$ século $\mathrm{XX}$ foi um período marcado por grandes transformações, principalmente na área tecnológica. Muitas foram as contribuições para a ciência, mudando decisivamente a vida das pessoas. O que antes era impossível, até de se imaginar, agora é realidade. Por isso, a importância de estudar o papel das tecnologias na educação, seus reflexos no âmbito escolar, sendo, a escola, base fundamental para expressões sociais educativas e orientadas.

Segundo Timbane, Axt e Alves (2015, p. 772), “[...] Cada professor e cada escola precisam inventar seus próprios caminhos (propondo ações que levem em conta as necessidades e interesses dos alunos), embora politicamente possam se posicionar de modo articulado (professores e escolas)".

A escola, como local de desenvolvimento de competências de aprendizagem e habilidades da formação de valores cognitivos, emocionais, éticos e sociais (BRASIL, 2017), necessita buscar meios para que a tecnologia seja transformada em instrumentos pedagógicos que enriqueçam o processo de ensino-aprendizagem.

As tecnologias são pontes que abrem a sala de aula para o mundo, que representam, medeiam o nosso conhecimento do mundo. São diferentes formas de representação da realidade, de forma mais abstrata ou concreta, mais estática ou dinâmica, mais linear ou paralela, mas todas elas, combinadas, integradas, possibilitam uma melhor apreensão da realidade e o desenvolvimento de todas as potencialidades do educando, dos diferentes tipos de inteligência, habilidades e atitudes. (MORAN, 2007, p. 3).

Sob essa ótica, percebe-se que grande parte das escolas ainda se veem diante de entraves a serem vencidos, desde os recursos financeiros ao fator humano. É preciso que se rompam paradigmas educacionais antigos, com o intuito de construir propostas nas quais as mídias e as tecnologias possam estar inseridas, mantendo um olhar atento, inclusive às diferentes concepções de linguagem, relacionadas a diferentes momentos históricos e sociais.

Existem três concepções de linguagem que podem embasar a metodologia do professor de Língua Portuguesa: como expressão do pensamento, que considera existir uma relação direta entre linguagem e pensamento (se uma pessoa não se expressa bem, significaria que ela não pensa bem, sob a perspectiva mesmo da tradução de tudo que existe na mente humana, a partir do ponto de vista do emissor); como instrumento de comunicação, compreendida como um código (mecanismo mediador, sendo o caminho para que ocorra a comunicação, com a necessária presença de um emissor e também de um receptor na troca de conhecimentos acerca de um mesmo código); e como forma ou processo de interação, que entende a linguagem como um meio de ação e interação (na qual os interlocutores agem produzindo significados em decorrência de um contexto sócio-histórico e ideológico) (FUZA; OHUSCHI; MENEGASSI, 2011).

Adotando uma concepção de linguagem, o docente admite certa concepção de língua, ou seja, de ensino de língua. Conhecer as concepções de linguagem colabora com o entendimento das diversas maneiras de idealizar a linguagem e aplicá-la na proposta metodológica no contexto de sala de aula. Alguns documentos que norteiam a educação básica, como os Parâmetros Curriculares Nacionais - PCN e a Base Nacional Comum Curricular BNCC, são orientados pela última concepção de linguagem, que vislumbra a interação.

Em tais documentos, assume-se a perspectiva enunciativo-discursiva de linguagem, sendo, a linguagem, "uma forma de ação interindividual orientada para uma finalidade específica; um processo de interlocução que se realiza nas práticas sociais existentes numa sociedade, nos distintos momentos de sua história" (BRASIL, 1998, p. 20). 
Neste trabalho, lançamos um olhar mais detido sobre a BNCC, a abordagem dos gêneros do discurso e, sobretudo, dos gêneros digitais, com ênfase no vídeo-minuto, sendo importante conhecer um pouco sobre o referido documento normativo que orienta a elaboração dos currículos escolares, tendo sua terceira versão publicada em 2017.

Tal versão traz novidades sobre a amplitude do uso de tecnologias nas salas de aula de Língua Portuguesa e a utilização dos gêneros digitais. A BNCC (2017) objetiva promover a unificação de saberes básicos necessários para a educação de qualidade, tendo caráter normativo e traçando diretrizes para que os alunos construam sua aprendizagem a partir do desenvolvimento de diferentes capacidades durante a trajetória escolar.

Nosso artigo tem como foco as considerações sobre o ensino de Língua Portuguesa, a partir dos gêneros do discurso, com fundamentação nos estudos de Bakhtin (1997), segundo o qual "[...] cada enunciado particular é individual, mas cada campo de utilização da língua elabora seus tipos relativamente estáveis de enunciados, os quais denominamos gêneros do discurso." (BAKHTIN, 1997, p. 292). O autor refere-se ainda à multiplicidade de gêneros, afirmando que "[...] a riqueza e diversidade dos gêneros do discurso são infinitas porque em cada campo dessa atividade é integral o repertório de gêneros do discurso, que cresce e se diferencia à medida que se desenvolve e se complexifica um determinado campo" (BAKHTIN, 1997, p. 292).

Pertinente para os estudos que nos propomos, voltados para os gêneros digitais, é saber que, apesar da referida estabilidade, o autor também demonstra que os gêneros não são estáticos: modificam-se diante de fatores contextuais, dinâmica de uso, com o passar do tempo, além de ser possível observar produções híbridas, com características de mais de um gênero (BAKHTIN, 1997).

Um exemplo de tal mudança, novamente pensando nos gêneros discursivos digitais, é o e-mail, que pode trazer elementos do gênero carta, como a saudação inicial, a forma de desenvolvimento, a saudação final e a assinatura. O e-mail também possibilita o envio de outros formatos, como o anúncio publicitário, sendo comum a difusão de propaganda por meio dele, quando passamos a vê-lo não somente como gênero, mas também como um suporte. No gênero carta pessoal, em seu formato mais simples, a escrita é manual e o tempo de chegada da informação é longo, devido à necessidade de um portador ou envio via Correios. A escrita do e-mail é digital, com o uso do computador ou smarthphones, sendo transmitido de forma instantânea por meio da internet. Nesse caso, observamos a atuação da tecnologia na facilitação e partilha das informações em tempo real.

A BNCC traz vários exemplos de gêneros discursivos, convencionais e digitais, que podem ser trabalhados na escola, conforme veremos no decorrer deste trabalho, além de demonstrar a necessidade de levar os estudantes à reflexão sobre de que modo utilizam as ferramentas tecnológicas, tratando de questões como limites para a exposição pessoal na web e buscando desenvolver habilidades para que avaliem até onde são fidedignos os conteúdos aos quais temos acesso em pesquisas virtuais (BRASIL, 2017).

Lilian Amaral da Silva (2010) afirma que a tecnologia vem se mostrando de suma importância no desenvolvimento da humanidade e que se faz necessário que a escola também adira a essa tecnologia, pois o educando é impactado diretamente pelas mais diversas mídias, sendo necessário surgirem mudanças na prática do educador, ofertando ao educando um ensino inovador e eficaz via uso das Tecnologias Digitais da Informação e Comunicação - TDIC.

Entendemos, portanto, ser necessário que a escola não fique alheia às mudanças tecnológicas, buscando estratégias que contemplem tal inserção no espaço escolar, não esquecendo de desenvolver um trabalho que priorize a realidade de seus alunos. 


\section{Caminhos metodológicos}

Esta pesquisa classifica-se como qualitativa, baseando-se na pesquisa bibliográfica, por meio do suporte em livros e artigos da área de Letras, especialmente no tocante à BNCC e ao que ela destaca em relação ao ensino de Língua Portuguesa, inserido em um contexto social e nas diversas práticas de linguagem.

O recorte de caráter bibliográfico contempla ainda reflexões sobre os gêneros do discurso, principalmente os digitais, e o uso deles na educação, a exemplo do vídeo-minuto, uma das diversas possibilidades para executar práticas metodológicas que favorecem o ensino produtivo. A inserção de tais gêneros no ensino contempla diretrizes da BNCC, sobretudo, e de outros documentos norteadores do Ensino Básico.

A fim de aprofundar os estudos sobre os gêneros na escola, ao escolhermos o vídeominuto, adotamos também o método de pesquisa descritiva, e analisamos detalhadamente algumas produções do gênero realizadas por estudantes, levando em conta a revisão de literatura e o que as diretrizes educacionais propõem, de modo a elencar atividades já realizadas e possíveis de serem replicadas em sala de aula.

\section{O vídeo-minuto na BNCC}

A leitura nos leva a uma reflexão sobre o processo de evolução da educação ao longo do tempo. Termos uma visão desse processo é importante para entendermos o atual quadro da educação e suas características contemporâneas. Hoje, as informações nos chegam rapidamente e o que demorava uma década para mudar ocorre com rapidez.

O processo de ensino-aprendizagem é exemplo disso, pois podemos observar que tais mudanças, no que se refere às novas práticas educacionais, acarretam diretamente a forma de serem introduzidas nas salas de aulas. No processo de ensino-aprendizagem, mudanças são sempre bem-vindas quando visam melhorar o rendimento escolar.

Assim, a educação também é beneficiada com tantos avanços tecnológicos, visto que nas práticas de ensino-aprendizagem absorve-se esse processo com a inserção das novas tecnologias na educação, as chamadas "mídias na educação", que estão sendo mais utilizadas, tanto em instituições de nível fundamental e médio como acadêmicas.

As novas tecnologias educacionais, referindo-nos às mídias na educação, são instrumentos eficazes nas mais recentes propostas pedagógicas, pois são capazes de transformar ou modificar a didática das aulas, e mesmo revolucionar métodos de ensino-aprendizagem. Logo, uma escola bem aparelhada, associada a um bom planejamento e a educadores qualificados, torna possível ações de inclusão digital e letramento de alunos e professores.

É pertinente ressaltar que o uso das tecnologias não oprime as outras práticas pedagógicas como, por exemplo, a sala de aula com o velho e bom quadro, mesmo que as novas ferramentas estejam a cada dia sendo mais utilizadas. Quem diria que um dia fôssemos estudar através de um computador, assistir a aulas via satélite ou ainda fazer uma graduação a distância com o uso da internet? Pois bem, estamos em um mundo globalizado e cheio de informações que não param de ser introduzidas no cotidiano.

Quando pensamos no impacto que as inovações oriundas da sociedade da informação ou era digital causam na educação, é possível perceber que os estudantes hoje têm acesso a uma infinidade de recursos tecnológicos, os quais influenciam o seu modo de estudar, de aprender, pesquisar e perceber sua cultura e seu mundo. $\mathrm{O}$ professor, nesse contexto, enfrenta o desafio ou o dilema de apropriar-se desses recursos e utilizá-los de forma significativa no processo ensino-aprendizagem; além disso, há aqueles que ainda não estão 
inseridos nesse universo tecnológico. (SANTOS; SCARABOTTO; MATOS, 2011, p. 15841).

Portanto, devemos refletir sobre o impacto de toda essa tecnologia no ensino de Língua Portuguesa, tendo em vista que o mundo das linguagens se modifica na revolução digital porque surgem outros meios de suporte para a disseminação das formas de ler, escrever e aprender.

A geração desses nativos alterou, assim, definitivamente, os rumos da Comunicação, bem como da Educação. Logo, não podemos pensar a Comunicação e nem a Educação a partir de paradigmas retrógrados, porque os avanços tecnológicos mudaram a forma de ser, agir e pensar da sociedade. [...] Assim, a Geração Y é caracterizada pelas múltiplas competências e habilidades sensórios verbais e visuais que possuem e utilizam para se comunicarem. (COELHO, 2012, p. 89, grifos da autora).

Partindo desse pressuposto, e das demandas sociais do século XXI, na área de Língua Portuguesa, os documentos oficiais norteadores já orientam sobre os processos de ensinoaprendizagem, tendo como base o uso das tecnologias, como vemos na BNCC. Observamos que a BNCC (2017, p. 65) dialoga com os demais documentos e orientações curriculares produzidos nas últimas décadas, apontando para as novas práticas sociais de linguagem, inclusive, especificamente, o componente Língua Portuguesa, buscando atualização "em relação às pesquisas recentes da área e às transformações das práticas de linguagem ocorridas neste século", que se devem, em grande parte, ao desenvolvimento e à adoção das TDIC, a serem utilizadas de forma qualificada e ética, conforme prevê.

As práticas de linguagem contemporâneas não só envolvem novos gêneros e textos cada vez mais multissemióticos e multimidiáticos, como também novas formas de produzir, de configurar, de disponibilizar, de replicar e de interagir. (BRASIL, 2017, p. 66).

O diálogo entre os gêneros digitais e os "gêneros consagrados" também é observado na própria BNCC, pois esses últimos permanecem, em concomitância com os novos, sendo necessário também voltar o olhar para os novos letramentos digitais, a exemplo da produção do vídeo-minuto, gênero privilegiado neste artigo e que analisaremos detidamente mais à frente.

Não se trata de deixar de privilegiar o escrito/impresso nem de deixar de considerar os gêneros e práticas consagrados pela escola, tais como notícia, reportagem, entrevista, artigo de opinião, charge, tirinha, crônica, conto, verbete de enciclopédia, artigo de divulgação científica etc., próprios do letramento da letra e do impresso, mas de contemplar também os novos letramentos, essencialmente digitais. (BRASIL, 2017, p. 67).

A inserção dos gêneros digitais, com grande ênfase nos novos letramentos, inclusive se compararmos com outros documentos de orientação educacional, é justificada por ser "mais recente e ainda pouco usual" a articulação de tais letramentos e da cultura digital com o currículo, havendo também a atenção devida à escrita e à oralidade (BRASIL, 2017, p. 67).

$\mathrm{Na}$ Base Nacional Comum Curricular, temos a centralidade do texto, em seu sentido amplo, no fomento ao trabalho com os inúmeros gêneros do discurso, envolvendo "atividades de leitura, escuta e produção de textos em várias mídias e semioses", e, "dessa forma, a BNCC procura contemplar a cultura digital, diferentes linguagens e diferentes letramentos, desde 
aqueles basicamente lineares, com baixo nível de hipertextualidade, até aqueles que envolvem a hipermídia." (BRASIL, 2017, p. 68).

Dentre os vários gêneros digitais contemplados pela BNCC, alguns já estão inseridos de forma bastante difundida no cotidiano daqueles que utilizam comumente as ferramentas digitais, como as redes sociais, a exemplo do gif e do meme.

É abordando a natureza de tais gêneros que a BNCC se refere também ao vídeo-minuto, tendo a suposição de sua produção citada como "resultado de um trabalho de pesquisa sobre produções culturais" para a qual "ainda que um nível de análise possa/tenha que existir, as habilidades mobilizadas estariam mais ligadas à síntese e percepção das potencialidades e formas de construir sentido das diferentes linguagens." (BRASIL, 2017, p. 67).

O gênero vídeo-minuto volta a ser referido pela BNCC no Eixo Leitura. Ao versar sobre as condições de produção e recepção textual, menciona-se a busca por refletir sobre as transformações com o desenvolvimento das TDIC, o uso do hipertexto, a hipermídia, o aparecimento da Web 2.0, e ainda

\begin{abstract}
Analisar as diferentes formas de manifestação da compreensão ativa (réplica ativa) dos textos que circulam nas redes sociais, blogs/microblog, sites e afins e os gêneros que conformam essas práticas de linguagem, como: comentário, carta do leitor, post em rede social, gif, meme, fanfic, vlogs variados, political remix, charge digital, paródias de diferentes tipos, vídeos-minutos, e-zines, fanzines, fanvídeo, vidding, gameplay, walkthroug, detonado, machinima, trailer honesto, playlists comentadas de diferentes tipos, etc., de forma a ampliar a compreensão de textos que pertencem a esses gêneros e a possibilitar uma participação mais qualificada do ponto de vista ético, estético e político nas práticas de linguagem da cultura digital. (BRASIL, 2017, p. 71).
\end{abstract}

Dentre tantos gêneros digitais referidos na BNCC, a escolha por lançar nosso olhar sobre o vídeo-minuto justifica-se por algumas questões. A primeira delas é o destaque dado pelo próprio documento, que volta a mencionar o vídeo-minuto nas diretrizes específicas para a Língua Portuguesa no Ensino Fundamental, turmas de $6^{\circ}$ ao $9^{\circ}$ ano, tanto no campo das práticas de estudo e pesquisa quanto no campo artístico-literário.

Nas práticas de estudo e pesquisa, o vídeo-minuto é referido no tópico sobre estratégias de produção textual: "(EF69LP37) Produzir roteiros para elaboração de vídeos de diferentes tipos (vlog científico, vídeo-minuto, programa de rádio, podcasts) para divulgação de conhecimentos científicos e resultados de pesquisa, tendo em vista seu contexto de produção, os elementos e a construção composicional dos roteiros.” (BRASIL, 2017, p. 151).

No corpo do texto da BNCC (2017, p. 83), o vídeo-minuto é citado como forma de expressão tanto das culturas juvenis quanto possibilidade de forma de expressão na atuação na vida pública, contemplando as práticas de estudo e pesquisa, sendo viável pensar no vídeominuto como modo de apresentação de resultados de pesquisa, por exemplo.

A respeito do primeiro caso, podemos refletir sobre o uso nas redes sociais, como os vídeos curtos postados, por exemplo, no feed do Instagram e nos stories ou status, divulgações que podem ser realizadas não apenas nessa rede, mas também no Facebook e no WhatsApp, considerando as redes mais populares, sendo um gênero perfeitamente viável para postagem em outros espaços focados no compartilhamento de vídeos, como o Youtube e o Vimeo.

No campo artístico-literário, esse gênero digital é incluso no ponto que se relaciona com a leitura:

(EF69LP46) Participar de práticas de compartilhamento de leitura/recepção de obras literárias/ manifestações artísticas, como rodas de leitura, clubes de leitura, eventos de contação de histórias, de leituras dramáticas, de 
apresentações teatrais, musicais e de filmes, cineclubes, festivais de vídeo, saraus, slams, canais de booktubers, redes sociais temáticas (de leitores, de cinéfilos, de música etc.), dentre outros, tecendo, quando possível, comentários de ordem estética e afetiva e justificando suas apreciações, escrevendo comentários e resenhas para jornais, blogs e redes sociais e utilizando formas de expressão das culturas juvenis, tais como, vlogs e podcasts culturais (literatura, cinema, teatro, música), playlists comentadas, fanfics, fanzines, e-zines, fanvídeos, fanclipes, posts em fanpages, trailer honesto, vídeo-minuto, dentre outras possibilidades de práticas de apreciação e de manifestação da cultura de fãs. (BRASIL, 2017, p. 155).

Temos, no entanto, outras motivações para trabalharmos com o gênero vídeo-minuto. Uma delas é a importância que o vídeo, em si, possui atualmente como meio de expressão, tendo se tornado corriqueira a produção de vídeos pelas mais diversas pessoas, de diferentes faixas etárias, poder aquisitivo e níveis de formação, com objetivos diversos, a partir do acesso a tecnologias relativamente baratas, que se popularizaram, sobretudo, os smarthphones.

Isso nos leva a outro ponto importante que precisa ser considerado ao pensarmos a relevância e a potencialidade do trabalho com esse gênero digital no âmbito escolar, uma questão de contexto social: a gradativa democratização do acesso aos meios de produção de conteúdo digital, mais especificamente para captação de imagens em movimento, bem como recursos de edição e espaços acessíveis para a publicização e compartilhamento dos conteúdos produzidos em vídeo, disponíveis on-line, gratuitamente e de fácil manuseio.

A questão da curta duração do vídeo-minuto também é um ponto importante, levando em conta todas as etapas: a produção do material, a adequação aos espaços de publicização, como as redes sociais referidas, e mesmo pensando em alcance e no perfil do público, considerando que um vídeo breve, em tais canais de divulgação, tem mais possibilidades de ser visualizado por completo. Essa característica desse gênero digital, relativa à duração, conforme indica a própria BNCC (2017), é um fator interessante ao ser trabalhado no ambiente educacional por instigar os alunos a exercitarem suas habilidades de sintetização.

\section{O Minuto Lumière e outros usos do vídeo-minuto}

Para refletir sobre as potencialidades do vídeo-minuto no espaço escolar, propomos observar alguns resultados de um projeto educacional da área de cinema e direitos humanos, o Inventar com a diferença, promovido pelo departamento de cinema da Universidade Federal Fluminense e a Secretaria de Direitos Humanos da Presidência da República, que foi desenvolvido com multiplicadores da área de audiovisual em todo o país.

Tais multiplicadores locais realizaram ações em escolas públicas e a formação de professores para que estivessem aptos a continuarem com a realização das atividades vinculadas ao audiovisual no ambiente escolar de maneira autônoma. Assim, os saberes e práticas do projeto eram compartilhados mesmo com educadores sem qualquer experiência com as técnicas e a linguagem audiovisual, que se tornariam novos multiplicadores (MIGLIORIN et al, 2014).

Quatro exercícios compõem as propostas básicas, primeiras experiências a serem realizadas com os estudantes, momento no qual "os estudantes tomam contato com elementos básicos da linguagem cinematográfica e ao mesmo tempo intensificam a relação com o outro, com o território e com as diferenças que o compõe - questões essenciais quando tratamos de direitos humanos" (MIGLIORIN et al, 2014, p. 21).

Um desses quatro exercícios chama-se Minuto Lumière. Conforme consta na cartilha do projeto, o nome desse exercício traz uma referência direta aos precursores do cinema: 
Considerado um marco inicial da história do cinema, em 1895, os Irmãos Lumière inventam o cinematógrafo, um aparelho que permite registrar uma série de instantâneos fixos (fotografias) que, quando projetados, criam uma ilusão de movimento. Com o cinematógrafo imóvel, as imagens eram filmadas em rolos de películas com cerca de 17 metros, atingindo aproximadamente 50 segundos de duração. (MIGLIORIN et al, 2014, p. 37).

O exercício proposto, o Minuto Lumière, consiste na produção de um plano, um vídeo com duração aproximada de um minuto, gravado com câmera fixa, nos moldes desses breves filmes feitos no início da história do cinema, na época, assim realizados por limitações tecnológicas (MIGLIORIN et al, 2014).

A realização de um MINUTO LUMIÈRE envolve três gestos fundamentais:

- A escolha - o que se quer filmar? Pessoas, gestos, sons, cores, luzes?

- A disposição - o posicionamento das coisas em relação umas às outras: onde coloco a minha câmera para captar esses elementos que escolhi filmar? De que forma disponho esses elementos diante da câmera para que sejam mais significativos, o que incluo ou deixo de fora do quadro?

- $\quad$ ataque - refere-se a agir, determinar o momento preciso para iniciar um minuto de filmagem. Qual é o momento para acionar o botão de gravação? (MIGLIORIN et al, 2014, p. 40, grifos do autor).

O registro em vídeo de recortes breves do cotidiano escolar ou da cidade na qual os estudantes vivem pode ser visto em diversos exercícios do Minuto Lumière produzidos a partir do Inventar com a diferença. Trazemos três exemplos de produções dos alunos da Escola Municipal Vila Fazendinha, localizada em Belo Horizonte, Minas Gerais, disponibilizadas no canal do projeto, que podem ser acessadas pelo Vimeo. Tais exercícios são bastante distintos entre si, fato que cabe registro, pois aí reside a expressão de subjetividade e a liberdade criativa dos alunos.

No primeiro, vemos uma aluna vestida com o uniforme da escola, de camiseta verde e short azul, usando sandálias, sentada em uma escada de degraus espaçados, de concreto, que têm aspecto sujo, marcados pelo tempo e pela umidade. A garota e a escada ocupam o centro do plano. A menina acaricia um gato tigrado, de pelo alaranjado, sentado em seu colo, e olha para ele, atenta. Vaza no áudio captação do ambiente, som do movimento de crianças, bem como trechos de um diálogo entre um adulto e uma criança, provavelmente um multiplicador do projeto dando instruções ao aluno que produz o exercício. Já nos segundos finais da gravação, outro aluno, de calça comprida, sandálias e casaco, atravessa o plano, entrando pela esquerda do quadro, passando pela escada, por trás da garota, e chegando ao lado direito, mas sendo captada, na maior parte do tempo, somente parte de seu corpo, até que ele se agacha, aparecendo por completo, posicionando-se, intencionalmente, dentro do quadro (INVENTAR..., 2014a).

O segundo vídeo traz ao centro um grupo de oito meninas, vestidas com uniforme escolar, provavelmente no recreio da escola, no espaço do pátio, que brincam juntas, pulando elástico, conversam entre si, em alguns momentos, em tom mais exaltado. Algumas, vez por outra, olham furtivamente para a câmera, riem, colocam a mão sobre o rosto, ou mesmo saem intencionalmente do quadro, o que demonstra a timidez e certo desconforto diante da consciência de estarem sendo filmadas, enquanto outras agem normalmente (INVENTAR..., 2014b).

No terceiro, o plano é gravado do alto de uma ladeira, sendo possível ver, à esquerda do quadro, um homem de meia idade, de camisa rosa claro, bermuda quadriculada e chinelos, com as mãos na cintura, em pé, em frente a uma casa, olhando para a câmera. A ladeira é asfaltada, 
vemos várias residências, nos dois lados da rua, algumas árvores, carros estacionados, dentre eles, um caminhão baú de mudança, pessoas caminhando na parte mais baixa, ao fundo do quadro, inclusive uma carroça puxada a cavalo. No áudio, é possível ouvir um adulto dando orientações ao aluno que produz o vídeo, informando que, nesse exercício, não pode mexer a câmera, pois assim eram as gravações com o cinematógrafo. $\mathrm{O}$ homem à esquerda do quadro vira-se de costas para a câmera e começa a descer pela calçada, até parar. Um aluno invade o quadro pelo lado esquerdo, balançando os braços, e fica parado brevemente, de braços cruzados, sorrindo para a câmera, até abrir os braços novamente e sair de quadro, correndo pelo lado direito. Vemos outra passagem intencional e rápida de um corpo em frente à câmera, muito perto, fato comentado pelo aluno-realizador. Por fim, um carro passa diante à câmera, formando, por meio da janela vazada, uma moldura que dá a ver o fundo do quadro (INVENTAR..., 2014c).

Diante da reclamação do aluno, afirmando que o colega teria passado muito perto da câmera, ouvimos a voz adulta mencionar que, ao levantar tal questão, ele estava se portando como um diretor, por estar ciente de suas escolhas. De fato, era exatamente isso que o aluno fazia: realizando escolhas, definindo o que queria ou não que fosse enquadrado e de que forma, pensando em composição de plano, utilizando seu conhecimento prévio sobre gramática audiovisual e adquirindo novos, via experimentação.

É importante ressaltarmos que o Minuto Lumière é um exercício possível de ser realizado dentro do gênero vídeo-minuto, mas outras produções, de estruturas diferentes, sem o uso do plano fixo, portanto, com a inserção de cortes, movimentação de câmera, trilha sonora e recursos gráficos, também podem ser utilizadas em novas propostas de produção. Poderíamos considerá-lo, portanto, um subgênero do vídeo-minuto, observando o conceito de Bakhtin (1997), que entende o gênero enquanto tipo relativamente estável de enunciado e que possui características reconhecíveis.

O próprio projeto Inventar com a diferença disponibiliza na internet outros vídeos, resultados de produções documentais, de aproximadamente um minuto, intituladas como "Pílulas", que não possuem a estruturação básica do exercício apresentado anteriormente, em referência aos Irmãos Lumière.

Outra iniciativa semelhante, também realizada pelo Inventar Bagé, núcleo do projeto na cidade, foi a produção de um curta-metragem, com menos de dois minutos de duração, realizado por alunos do Instituto Federal de Educação, Ciência e Tecnologia Sul-rio-grandense - IFSul, sob o título Expressões. Conforme a própria sinopse, o filme "mostra gestos, emoções, sensações, expressões das pessoas durante uma tarde movimentada na cidade de Bagé, RS." (EXPRESSÕES..., 2017).

O vídeo é composto por vários registros breves, de pessoas de diferentes faixas etárias, sorrindo, namorando, interagindo entre amigos, havendo o uso de vários planos-detalhe, enquadrando as mãos que seguram algo, que batem palmas, que descansam sobre um banco de praça, que seguram outra mão, além de outros recortes, como pés que se equilibram na travessia de um meio-fio, um riso, um beijo (EXPRESSÕES..., 2017).

Tal produção, dos alunos do IFSul, demonstra o quanto o vídeo-minuto pode resultar em uma representação de sensibilidade, um olhar desautomatizado sobre a cidade em que se vive, conduzir à observação atenta do cotidiano e das relações com o outro, conforme a arte, em todas as suas formas, é capaz de promover.

Esses exemplos demonstram o potencial do vídeo-minuto para o uso no campo artísticoliterário. Mas também trazemos menção a outros conteúdos que vislumbram a utilização do gênero a partir das práticas de estudo e pesquisa. Para tanto, chamamos a atenção para os materiais diversos, de referência, disponibilizados no site Nova Escola, considerando o gênero digital que focamos neste trabalho. São propostas específicas sobre o vídeo-minuto, como o plano de aula "Conhecendo a estrutura de um vídeo-minuto" (ROCHA, s/d), indicado para 
atividades de Língua Portuguesa direcionadas ao $8^{\circ}$ ano do Ensino Fundamental, com menção direta às habilidades referidas pela BNCC que envolvem tal gênero.

Como objetivo do plano, indica-se "analisar a construção composicional e os elementos paralinguísticos (volume de voz e ritmo) e cinésicos (sincronia das falas com as imagens) em vídeo-minuto, com vistas ao aprimoramento de apresentações orais realizadas a fim de divulgar o conhecimento" (ROCHA, s/d). O plano traz como informações sobre o gênero a seguinte indicação: "O vídeo-minuto tem como objetivo homenagear, criticar, informar ou gerar humor, tendo um tempo determinado em torno de 1 minuto." (ROCHA, s/d).

Nessa aula, os alunos são instigados a refletirem sobre um minuto ser ou não muito tempo; a possibilidade de transmitir informações nesse tempo; sendo indicada a exibição de um vídeo de um minuto e cinquenta e dois segundos de duração, com a temática "As mortes mais ESTÚPIDAS causadas por SELFIES!", escolha justificada no plano por esse ser um tema que geraria interesse, já que faz parte do cotidiano dos alunos, e daria a oportunidade de fazê-los refletir "quanto aos riscos do uso descontrolado do celular" (ROCHA, s/d), por meio da realização de debate, após a exibição do vídeo, e resposta individual de exercício sobre a temática.

Enquanto o primeiro plano de aula que destacamos é mais focado no reconhecimento do gênero vídeo-minuto e no fomento à reflexão, o segundo, "A produção de um vídeo-minuto a partir de slides de apresentação", traz como finalidade a seleção e a organização de verbetes enciclopédicos, escolha de imagens e produção de um vídeo-minuto a ser utilizado em apresentações orais (ROCHA, s/d).

O plano de aula prevê que os alunos assistam a um vídeo e leiam um texto sobre como segurar o smartphone de maneira correta para fotografar e gravar, questionando-os se a apresentação em vídeo ou o material escrito seriam mais dinâmicos. Iniciando a parte prática, há sugestão de organização dos alunos em grupos, com realização da atividade no laboratório de informática, ou avisando-os previamente, para que, aqueles que possuam, tragam seus smarthphones, tomando o cuidado em incluir, em cada grupo, um estudante com mais habilidade para edição (ROCHA, s/d).

Conforme as orientações, os alunos devem ser informados que "o objetivo da aula é selecionar imagens e organizá-las em programas de edição de vídeos ou slides de apresentação, que se transformarão em vídeos, como preparo para a produção de um vídeo-minuto com duração de no máximo $1 \mathrm{~min} 40 \mathrm{seg}$, sobre o assunto do verbete lido" (ROCHA, s/d). Para tanto, indica-se a produção de um roteiro escrito, como base para narração, com os dados do verbete; a seleção de fotos de internet que possam ilustrar o roteiro; e a organização de tais fotos de modo que a edição resulte em um vídeo (ROCHA, s/d).

\section{Considerações finais}

Conforme vimos, na BNCC, o texto ganha um papel central, dentro da perspectiva enunciativa-discursiva, no que concerne à definição dos conteúdos, das habilidades e objetivos, partindo sempre dos gêneros discursivos que circulam na sociedade, inclusive os digitais. Por conseguinte, a BNCC deixa claro que compete ao componente curricular Língua Portuguesa oportunizar aos alunos experiências que ampliem os letramentos, de maneira a proporcionar a participação significativa e crítica nas variadas práticas sociais engendradas pela escrita, oralidade e outras linguagens (BRASIL, 2017, p. 66), o que podemos observar ocorrer concretamente nos exemplos apresentados em nossa análise sobre o uso do vídeo-minuto.

Tais produções dialogam diretamente com a concepção de linguagem enquanto interação, conforme a orientação dos $\mathrm{PCN}$ e da BNCC. Interação que se dá no processo de orientação, produção e veiculação dos vídeos, entre os próprios estudantes, entre os alunos e o docente, com o espaço escolar, e mesmo com o espaço social no qual estão inseridos. 
Cabe ainda reforçarmos a pertinência da visão de Bakhtin (1997) a respeito da dinamicidade dos gêneros discursivos, pois observamos que o vídeo-minuto é um gênero que se modifica, apresentando grande potencial de transformar-se, de acordo com a forma de uso, o contexto e o objetivo, que, em nosso recorte, vislumbra o campo educacional.

Vale ressaltar ainda a presença das TDIC dentro da escola enquanto algo palpável, legítimo, como, por exemplo, os celulares, que hoje dispõem de grande aparato tecnológico, possibilitando acesso à internet, captação de imagens, criação de vídeos, acesso a jogos, etc. Tais equipamentos podem ser uma preocupação para professores, por tirarem a atenção dos alunos, tendo seu uso restringido em várias escolas, mas também podem ser aproveitados como ferramentas educativas nas aulas de Língua Portuguesa quando abordados de forma criativa, pautadas em um contexto de interação, tornando as aulas mais envolventes e produtivas.

$\mathrm{O}$ vídeo-minuto figura, nesse contexto, enquanto gênero digital versátil, que pode ser usado tanto para produções de maior subjetividade, vinculadas ao campo artístico-literário, à experimentação e à criação, quanto forma de apresentação de conhecimentos científicos distintos e resultados de pesquisa. E ainda, quando utilizado pelo docente para a apresentação de conteúdos, tornar a aula mais dinâmica, por meio da inserção de vídeos breves e que condensam informações relevantes para o aprendiz, capazes de concentrar a atenção dos alunos.

Assim, compreendemos ser necessário que a escola busque mecanismos que possibilitem a melhoria do processo de ensino-aprendizagem, inserindo os alunos em práticas e eventos de letramentos que os levem à reflexão e à interiorização do conteúdo curricular ao cerne de suas vidas, mediando o trabalho com os gêneros discursivos, incluindo os digitais, fundamentados em práticas sociais, cumprindo o seu papel no tocante à formação das novas gerações.

\section{Referências}

BAKHTIN, Mikhail. Os gêneros do discurso. In: BAKHTIN, Mikhail. Estética da criação verbal. São Paulo: Martins Fontes, 1997. p. 279-326.

BRASIL. Ministério da Educação. Secretaria da Educação Básica. Base nacional comum curricular. Brasília, DF, 2017. Disponível em:

http://basenacionalcomum.mec.gov.br/images/BNCC EI EF 110518 versaofinal site.pdf. Acesso em: 19 abr. 2019.

BRASIL. Secretaria de Educação Fundamental. Tratamento didático dos conteúdos. In: BRASIL. Parâmetros curriculares nacionais: língua portuguesa. Brasília: Secretaria de Educação Fundamental, 1998. Disponível em:

http://portal.mec.gov.br/seb/arquivos/pdf/livro02.pdf. Acesso em: 19 abr. 2019.

COELHO, Patrícia Margarida Farias. Os nativos digitais e as novas competências

tecnológicas. Texto livre: linguagem e tecnologia, UFMG, v. 5, n. 2, p. 88-95, 2012.

Disponível em: http://www.periodicos.letras.ufmg.br/index.php/textolivre/article/view/2049.

Acesso em: 15 jul. 2019.

EXPRESSÕES - Inventar com a Diferença. Inventar Bagé. 1 vídeo (1min44s). 24 abr. 2017.

Disponível em: https://www.youtube.com/watch?v=ycdB-UYS7-M. Acesso em: 18 jul. 2019. FUZA, Ângela Francine; OHUSCHI, Márcia Cristina Greco; MENEGASSI, Renilson José. Concepções de linguagem e o ensino da leitura em língua materna. Linguagem \& Ensino, Pelotas, v.14, n.2, p. 479-501, jul./dez. 2011. Disponível em:

http://www.rle.ucpel.tche.br/index.php/rle/article/view/36. Acesso em: 15 abr. 2019.

INVENTAR com a diferença. E. M. Vila Fazendinha - Minuto Lumière I. Inventar com a diferença. Vimeo. 13 mai. 2014a. 1 vídeo (1min00s). Disponível em:

https://vimeo.com/95189831. Acesso em: 18 jul. 2019. 
INVENTAR com a diferença. E. M. Vila Fazendinha - Minuto Lumière II. Inventar com a diferença. Vimeo. 13 mai. 2014b. 1 vídeo (1min01s). Disponível em:

https://vimeo.com/95190631. Acesso em: 18 jul. 2019.

INVENTAR com a diferença. EM Vila Fazendinha - Minuto Lumière III. Inventar com a diferença. Vimeo. 13 mai. 2014c. 1 vídeo (1min02s). Disponível em:

https://vimeo.com/95190630. Acesso em: 18 jul. 2019.

MIGLIORIN, César et al. Inventar com a diferença: cinema e direitos humanos. Niterói:

Editora da UFF, 2014.

MORAN, José Manuel. As mídias na educação. In: MORAN, José Manuel. Desafios na

Comunicação Pessoal. 3. ed. São Paulo: Paulinas, 2007. p. 162-166. Disponível em:

http://www.eca.usp.br/prof/moran/site/textos/tecnologias_eduacacao/midias_educ.pdf. Acesso em: 19 abr. 2019.

ROCHA, Gleiciane Rosa Vinote. Plano de aula - A produção de um vídeo-minuto a partir de slides de apresentação. Nova Escola. s/d. Disponível em: https://novaescola.org.br/plano-deaula/4373/a-producao-de-um-video-minuto-a-partir-de-slides-de-apresentacao. Acesso em: 19 jul. 2019.

ROCHA, Gleiciane Rosa Vinote. Plano de aula - Conhecendo a estrutura de um vídeominuto. Nova Escola. s/d. Disponível em: https://novaescola.org.br/plano-deaula/3579/conhecendo-a-estrutura-de-um-video-minuto. Acesso em: 19 jul. 2019. SANTOS, Marisilvia dos; SCARABOTTO, Suelen do Carmo dos Anjos; MATOS, Elizete Lucia Moreira. Imigrantes e nativos digitais: um dilema ou desafio na educação? Anais do X Congresso Nacional de Educação - EDUCERE, Curitiba, 2011. Disponível em: https://educere.bruc.com.br/arquivo/pdf2011/5409 3781.pdf. Acesso em:10 jul. 2019. SILVA, Lilian Amaral da. O uso da TV no desenvolvimento da consciência crítica na educação. 2010, Trabalho de Conclusão de Curso (Especialização em Mídias na Educação) Universidade Federal do Rio Grande do Sul - CINTED/UFRGS, Porto Alegre, 2010. Disponível em: https://www.lume.ufrgs.br/bitstream/handle/10183/141451/000991668.pdf?sequence=1. Acesso em: 20 abr. 2019.

TIMBANE, Sansão Albino; AXT, Margarete; ALVES, Evandro. O celular na escola: vilão ou aliado. NuevasIdeas en Informática Educativa, TISE, p. 768-773, 2015. Disponível em: http://www.tise.cl/volumen11/TISE2015/768-773.pdf. Acesso em: 19 abr. 2019. 